\title{
Quality Checks Logit Human Reliability (LHR): A New Model to Evaluate Human Error Probability (HEP)
}

\author{
Gianpaolo Di Bona $\mathbb{D}^{1},{ }^{1}$ Domenico Falcone, ${ }^{1}$ Antonio Forcina, ${ }^{2}$ Filippo De Carlo $\left(\mathbb{D},{ }^{3}\right.$ \\ and Luca Silvestri ${ }^{4}$ \\ ${ }^{1}$ Department of Civil and Mechanical Engineering, University of Cassino and Southern Lazio, Cassino, Italy \\ ${ }^{2}$ Department of Engineering, University of Naples "Parthenope", Naples, Italy \\ ${ }^{3}$ Department of Engineering, University of Florence, Florence, Italy \\ ${ }^{4}$ Department of Engineering, University "Niccolò Cusano", Roma, Italy
}

Correspondence should be addressed to Gianpaolo Di Bona; dibona@unicas.it

Received 1 December 2020; Revised 19 March 2021; Accepted 29 March 2021; Published 9 April 2021

Academic Editor: Arturo J. Fern ndez

Copyright ( $\odot 2021$ Gianpaolo Di Bona et al. This is an open access article distributed under the Creative Commons Attribution License, which permits unrestricted use, distribution, and reproduction in any medium, provided the original work is properly cited.

\begin{abstract}
In the years, several approaches for human reliability analysis (HRA) have been developed. The aim of the present research is to propose a hybrid model to evaluate Human Error Probability (HEP). The new approach is based on logit-normal distribution, Nuclear Action Reliability Assessment (NARA), and Performance Shaping Factors (PSFs) relationship. In the research, shortcomings related to literature approaches are analyzed, especially the limitations of the working time. For this reason, PSFs after 8 hours (work standard) during emergency conditions were estimated. Therefore, the correlation between the advantages of these three methodologies allows proposing a HEP analysis during accident scenarios and emergencies; a fundamental issue to ensure the safety and reliability in industrial plants is emergency Mmnagement (EM). Applying EM methodology, two main aspects are analyzed: system reliability and human reliability. System reliability is strongly related to the reliability of its weakest component. During incidental situations, the weakest parts of the whole system are workers (human reliability) and accidental scenarios influence the operator's ability to make decisions. This article proposes a new approach called Logit Human Reliability (LHR) that considers internal and external factors to estimate human reliability during emergencies. LHR has been applied in a pharmaceutical accident scenario, considering 24 hours of working time (more than 8 working hours). The results highlighted that the LHR method gives output data more in conformity with data banks than the conventional methods during the stress phase in an accident scenario.
\end{abstract}

\section{Introduction}

The complexity of technological evolution has increased risks related to the management of industrial machines [1] and due to more and more frequent accident situations, emergency management (EM) in production systems has assumed an important role [2]. According to Sheridan and Ferrell [3], EM evaluates two fundamental parameters: system reliability and human reliability. For this reason, research about human reliability is growing in recent years. In this scenario, it is necessary to monitor the safety of critical infrastructures [4] since their failure could generate serious consequences on the environment and drastic emergency [5]. On the other hand, it is equally important to study human behavior during emergency conditions. A wrong choice of the operator could worsen emergency conditions; therefore, it is necessary to identify all factors that affect the operator's behavior [6].

Emergencies are definitively complex and dynamic; hence, operators must recognize, prevent, and solve problems that can generate accidents [7]. In the beginning, HRA has been developed in the nuclear field, where human error could have important consequences [2]. It is important to analyze and manage external and internal factors related to 
human reliability [8]. Risk management studies all factors to limit emergency conditions and reduce the consequences of human errors [9]. Human factors are an important element in accident scenarios [5]. HRA is a systemic approach that evaluates HEP during the working time, analyzing external and internal factors which could influence workers' performance $[10,11]$. The study of risk management is very complex because it looks like more and more advanced equipment. The present research aims to define a simulation model to represent different accident scenarios and their evolution. The simulation model returns actual values useful for studying the accident, the operators' behavior, and the impact on their choices. The article analyzes the most important HRA approaches. LHR method starts from the NARA model proposed by Kirwan et al. [12], the SPAR-H model proposed by Gertman et al. [13], and the Performance Shaping Factors (PSFs) dependence proposed by Boring [14]. By applying NARA and SPAR-H models, the basic human error probability $\left(\mathrm{HEP}_{\text {basic }}\right)$ has been evaluated, considering internal and external factors. The "external" factors depend on the work environment; they modify the working conditions, thus leading to errors. The "internal" factors are related to the individual's characteristics and individual psychophysical conditions of the operator.

However, NARA and SPAR-H models do not analyze the dependencies between the external environmental factors. Using PSFs, it is possible to value the influence of many external environmental factors, coming from the analysis of 82 real case studies.

The aim of this study is to propose a hybrid model, called Logit Human Reliability (LHR), for evaluating HEP in industrial plants during an emergency condition.

The proposed approach combines three methods of HRA: the NARA methodology, logit-normal distribution, and Boring's PSFs dependency. The fusion among these three methodologies allows developing a reliable simulator for HEP analysis during emergency conditions.

The human (internal) and environmental (external) factors that influence the operator's ability are both evaluated in the proposed approach. Boring's PSFs dependency considers the external factors, while the NARA methods consider the internal factors. The logit-normal distribution can be evaluated through basic HEP that will be corrected by PSFs. The proposed method uses logit function because it represents the "wear-out" condition of the human operator. Using logit distribution, HEP increase vs. time can be calculated.

LHR is structured in six steps: (1) preliminary analysis of the system; (2) definition and evaluation of generic tasks; (3) evaluation of the basic human error probability $\left(\mathrm{HEP}_{\text {basic }}\right)$; (4) definition and evaluation of PSFs; (5) definition and evaluation of PSFs relationship; (6) evaluation of $\mathrm{HEP}_{\mathrm{LHR}}$ using a combination of NARA and SHARP-H methods. The proposed strategy can overcome the shortcomings of traditional techniques: (1) NARA model does not consider PSFs, while SHAR-H model considers only independent PSFs; (2) SHAR-H and NARA consider generic tasks during 8 hours (working time); (3) NARA and SPAR-H models consider constant failure rate to evaluate HRA.
The proposed model has been validated in a pharmaceutical plant; in particular, the operator's behavior in a control room has been analyzed. The article is organized as follows: Section 2 analyzes the state of the art of HRA (human reliability analysis). In Section 3, the methodological research approach is presented. In Section 4, the case study is analyzed, while in Section 5, the results are presented and discussed. Finally, in Section 6, the conclusions and future developments are described.

\section{Literature Review}

Human Reliability Analysis (HRA) analyzes human reliability in a similar way to the analysis of system reliability [15]. According to Swain and Guttman [16], HRA methodologies have motivated many activities in research and development $[17,18]$.

Maintenance design is a crucial issue consisting of several activities to achieve levels of availability and to guarantee production capacity. The availability of a production system depends on the performance and connections of the machines and operators [19]. Maintenance design activities are based on HRA values collected by monitoring the condition of machines and human processes [20].

In general, three causes lead to an accident: system failures, natural events, and human errors [21].

In recent years, advanced technology has allowed creating reliability machines. However, the literature analysis shows that most of the accidents that occurred in critical infrastructures depend on human errors. HRA has been analyzed in pharmaceutical plants. Several authors analyzed human behavior in emergency conditions. For example, Jung et al. [22] analyzed the performance of the operator in a pharmaceutical plant. Houshyar and Imel [23] developed a simulation model of human behavior in a nuclear plant. Literature analysis divides HRA methodology into three different generations:

(a) First generation (1970-1990) focused on the skills and rules of human factors without considering social interest, management factors, and communication errors. Some first-generation approaches are as follows:

(i) Systematic Human Action Reliability (SHARP): it considers the integration of man and machines [24] and calculates HEP in seven steps [25, 26].

(ii) The Empirical Technique to Estimate the Operator's Error (TESEO): it considers five factors and calculates the HEP of the operator [27]. Checking the control room operator, Bello and Colombari [28] used TESEO to evaluate HEP in safety analysis of an industrial plant.

(iii) Accident Sequence Evaluation Program (ASEP): It is a simplified version of the THERP method [16]. ASEP has been applied to nuclear plants and uses the correlation between time and reliability to obtain HEP [29, 30]. 
(iv) Human Cognitive Reliability Correlation (HCR): It used SLIM factors to estimate HEP; SLIM equations have been revised to evaluate PSFs effect on human reliability [31].

(v) Technique for Human Error Rate Prediction (THERP): Sandia National Laboratories (SNL) in 1961 adopted THERP to estimate HEP in nuclear plants. Considering a number of activities, THERP identifies HEP in all process tasks. THERP analyzes some PSFs but not their effects on HEP [32].

(vi) Success Likelihood Index Method (SLIM): United States Nuclear Regulatory Commission developed in the 1980s [33] SLIM approach. It has been used in nuclear plants, but it can be easily applied to other plants. Expert judgment is formalized in SLIM to evaluate HEP. SLIM requires minimum data for HEP assessment [34].

(vii) Human error assessment and reduction technique (HEART): it has been developed in the early 1990s [35] in the United Kingdom nuclear plants. By identifying "generic tasks" (GTTs), the analyst can determine the HEP basic. This approach is very simple to apply and it reduces the effort to evaluate HEP [36].

(b) Second-generation methodologies (1990-2005) integrate internal and external factors affecting human reliability. In second-generation models, the factors which determine PSFs are derived by focusing on the environmental impact on the cognitive level. Some second-generation methodologies are as follows:

(viii) Cognitive Reliability and Error Analysis Method (CREAM): It is based on the Contextual Control Model (COCOM) [37]. Konstandinidou et al. [38] used this approach to implement a fuzzy model for HRA. CREAM provides a two-level approach to estimate HEP: the basic level and an extended one. The basic approach is developed to determine the HEP with PSFs values.

(ix) A Technique for Human Event Analysis (ATHEANA): It is the product of many studies sponsored by the U.S. Nuclear Commission and started in 1992 [39]. ATHEANA was designed to be a full scope HRA method, including the capability of performing predictive task analysis and retrospective event analysis.

(x) Standardized Plant Analysis Risk-Human RA (SPAR-H): It was a revised version of the ASP approach. SPAR-H has been applied to over 70 U. S. nuclear power plants. Rasmussen et al. [40] applied this approach to estimate HRA to the pharmaceutical industry. SPAR-H is based on eight PSFs: available time; stress/stressors; complexity; experience/training; procedures; ergonomics/human-machine interface; fitness for duty; work processes.

(c) In the last ten years, the shortcomings of the second-generation HRA have been overcome by third-generation methods [41]. Using the simulation system of human performance, third-generation methods are able to evaluate different scenarios that may challenge HEP during missions [42]:

(xi) Nuclear Action Reliability Assessment (NARA): It is an upgrade of the HEART method to (a) have a better fit to nuclear context, (b) consider errors of commission, (c) have substantial data support, (d) consider long time scale scenarios, and (e) have better guidance on usage. The main differences between NARA and HEART are (a) the grouping of the generic tasks, (b) the weights of the errorproducing contexts, and (c) the use of the COREDATA human error database in NARA.

Boring [14] proposed a dependence model between the PSFs. In addition to the human behavior simulation software, there are many geographic software programs that allow managing external environment during an incidental situation. Rauschert et al. [43] used GIS, a geographic interface, to manage emergencies. The research takes into account the external environment and its characteristics $[44,45]$. The development of the Internet and social networking is very useful for this type of application, especially in relation to the flow of information. Even Schafer, Ganoe, and Carroll [46] managed the planning of EM through geographical software. It examines the geospatial maps and develops plans and emergency procedures. Currion et al. [47] developed a simulation tool to manage coordination during an emergency. Another field of EM is the health facilities sector. Levi et al. [48] described the experience in developing and implementing the use of simulation software as a drilling technique used by Israeli hospitals. The application was developed using SIMAN/ARENA software. Cowan and Cloutier [49] described a required, role-intensive leadership simulation in emergency and disaster medicine management for fourth-year medical students. The simulation exercise is designed to provide an opportunity for federal medical students to experience a realistic combat or disaster environment similar to the environments in which they may be required to operate medical support systems. Christie and Levary [50], who used the simulation model "what-if," predicted the consequences of conceivable scenarios [51].

In this scenario, the present study starts from several shortcomings of HRA models in the literature $[52,53]$. The proposed model, called LHR, overcomes the limitations of the most conventional HRA methodologies, merging the advantages of NARA, PSFs, and SPAR-H models (Table 1).

The target of the present research is (1) to study the fundamental actions in incidental situations and (2) to analyze the causes of accidents to prevent them. Furthermore, the present research analyzed three limitations related to the NARA model: (1) HEP is limited to the first 8 hours of work [54]; (2) there is no dependency between the relationships of PSFs; (3) the failure rate is constant. LHR models try to overcome these shortcomings. 
TABLE 1: Conventional HRA method.

\begin{tabular}{|c|c|c|c|c|}
\hline Model & Authors & Advantages & Limitations & Domain \\
\hline HEART & William [30] & $\begin{array}{l}\text { Relatively quick to apply } \\
\text { Use of generic tasks }\end{array}$ & No environmental (external) tasks & Generic \\
\hline $\begin{array}{l}\text { SPAR- } \\
\mathrm{H}\end{array}$ & $\begin{array}{l}\text { Gertman et al. } \\
{[13]}\end{array}$ & $\begin{array}{c}\text { Useful approach for situations where a detailed } \\
\text { assessment is not necessary } \\
\text { Use of environmental tasks }\end{array}$ & $\begin{array}{l}\text { No correlation between environmental } \\
\text { (external) tasks }\end{array}$ & $\begin{array}{l}\text { Nuclear with } \\
\text { wider } \\
\text { application }\end{array}$ \\
\hline PSFs & Boring [14] & Use of correlation between environmental tasks & Absence of HEP evaluation & Generic \\
\hline NARA & $\begin{array}{l}\text { Kirwan et al. } \\
{[12]}\end{array}$ & $\begin{array}{c}\text { A nuclear-specific version of HEART } \\
\text { HEP evaluation }\end{array}$ & $\begin{array}{l}\text { No correlation between environmental } \\
\text { (external) tasks }\end{array}$ & Nuclear \\
\hline
\end{tabular}

\section{Logit Human Reliability (LHR)}

In this section, the proposed LHR model is described. The new approach combines three methods of HRA: the NARA methodology, logit-normal distribution, and Boring's PSFs dependency.

The human (internal) and environmental (external) factors that influence the operator's ability are both evaluated in the new approach. The starting model NARA is an upgrade of the HEART method. Boring's PSFs dependency considers the external factors, while the NARA method considers the internal factors. The logit-normal distribution is able to be evaluated through basic HEP that will be corrected by PSFs.

The model has been applied during a simulated emergency in a pharmaceutical plant, considering 24 hours of working time.

Step 1: Preliminary Analysis.

Identification of the activities to be simulated: it lists all activities performed by the decision-makers while working in nominal conditions and during an emergency. It is important to identify the accident scenarios considering the gravity of the situation; HEP will be associated with each of these activities, where HEP represents the unreliability of the operator. During an emergency, working time is a critical parameter that must be carefully evaluated. For example, Di Pasquale et al. [55] and Gertman and Blackman [56] simulated the HEP with the Weibull function, while Chiodo et al. [57] used a random function to evaluate human performance. Usually, LogitNormal function is selected during the "wear-out" phase of components. This phase can be compared to the stress phase of an operator during an accident scenario.

Starting from the above analysis, we have selected logit distribution to link HEP and operating time.

The human unreliability has been evaluated by the logit function of failure probability (equation (1)).

$$
g(t)=1-\frac{e^{(t-\mu / \sigma)}}{1+e^{(t-\mu / \sigma)}}
$$

where $\mu$ is the average value and $\sigma$ is the standard deviation.

Step 2: Identification of Human Activities (internal factors).
In this phase, generic tasks (GTTs) are defined, representing the internal factors of the operators [58]. Each GTT follows the logit function that represents the "wear-out" condition of the human operator. Using logit distribution, HEP will be calculated and the HEP increase vs. time is calculated. Table 2 describes the NARA GTTs, while $k$ is the human unreliability value of the 8 th hour of working time $[59,60], \lambda$ is the constant value of failure rate, $\mu$ is the mean time to failure, and $\sigma$ is the standard deviation. Assuming $\lambda=$ constant, we obtain the following:

$$
\begin{aligned}
\lambda & =-\frac{\ln \left(1-k_{24}\right)}{8}, \\
\operatorname{MTTF} & =\mu=\int_{0}^{\infty} t \cdot f(t)=\frac{1}{\lambda}, \\
\sigma & =\sqrt{\int_{0}^{\infty}(t-\mathrm{MTTF})^{2} \cdot \mathrm{f}(t) \mathrm{d} t} \\
& =\sqrt{\int_{0}^{\infty}\left(t-\frac{1}{\lambda}\right)^{2} \cdot \lambda e^{-\lambda \mathrm{t}} \mathrm{d} t,}
\end{aligned}
$$

where $f(t)=\lambda e^{-\lambda t}$ is the failure probability density function when $\lambda=$ constant (Table 2).

Step 3: Basic Human Error Probability ( $\left.\mathrm{HEP}_{\text {basic }}\right)$

The calculation of the basic error probability (influenced by GTTs) follows the logit distribution (equation (1)). The nominal distribution is theoretical and does not take into account the external environment factors. $\mathrm{HEP}_{\text {basic }}$ takes into account only the $k$ value (Table 2). The logit distribution is selected to describe the human unreliability during the "wear-out" when the failure rate grows up. The human unreliability value (Table 2 ) is the input value for equation (1), where $\mu$ and $\sigma$ are calculated using equations (3) and (4). The basic $\mathrm{HEP}_{\text {basic }}$ is determined as follows:

$$
\begin{aligned}
{\left[\mathrm{HEP}_{\text {basic }}\right]_{t 1}^{t 2} } & =\int_{t 1}^{t 2} 1-\frac{e^{(t-\mu / \sigma)}}{1+e^{(t-\mu / \sigma)}} \\
\mathrm{d} t & =\frac{1}{t 2-t 1}\left[t-\sigma \ln \left(1+e^{(t-\mu / \sigma)}\right)\right]_{t 1}^{t 2}
\end{aligned}
$$


TABLE 2: Generic tasks.

\begin{tabular}{|c|c|c|c|c|c|}
\hline $\mathrm{N}^{\circ}$ & GGT & $\begin{array}{c}k \\
(t=8 \mathrm{~h})\end{array}$ & $\lambda[1 / \mathrm{h}]$ & $\mu(\mathrm{h})$ & $\sigma(\mathrm{h})$ \\
\hline A1 & $\begin{array}{r}\text { Carry out simple single manual action with feed } \\
\text { necessarily with the pr }\end{array}$ & 0.0050 & -4 & 1596.00 & 618 \\
\hline A2 & $\begin{array}{l}\text { Start or reconfigure a system from the main control room following procedures, with } \\
\text { feedback. }\end{array}$ & 0.0010 & $.169 \cdot 10^{-5}$ & 2398 & 6010 \\
\hline A3 & Start or reconfigure a system from a local control panel following procedures, with feedback. & 0.0030 & $1.252 \cdot 10^{-4}$ & 798 & 2800 \\
\hline A4 & $\begin{array}{l}\text { Reconfigure a system locally using special equipn } \\
\text { boiler SRV using gagging equipment. Full }\end{array}$ & 0.0300 & 20 & & 413 \\
\hline A5 & $\begin{array}{l}\text { Judgment needed appropriate procedure to be followe } \\
\text { indications, situation covered by training }\end{array}$ & 0.0100 & & & 1004 \\
\hline A6 & $\begin{array}{l}\text { Completely familiar, well-designed highly pra } \\
\text { possible standards by highly motivated, highly t } \\
\text { of implications of failure with tin }\end{array}$ & 0.0001 & & 239 & 59995 \\
\hline $\mathrm{B}$ & Routine check of plant sta & 0.0300 & -3 & & 413 \\
\hline B2 & $\begin{array}{c}\text { Restore a single train of a system to correct operational status after test following } \\
\text { procedures. }\end{array}$ & 0.0070 & & 3 & 1316 \\
\hline B3 & $\begin{array}{c}\text { Set system status as part of routine operations using strict administratively controlled } \\
\text { procedures. }\end{array}$ & 0.0007 & $0^{-5}$ & 342 & 8566 \\
\hline B & Calibrate plant equipment usin & & & & 2800 \\
\hline B5 & S & 0.0300 & & 787.94 & 413 \\
\hline $\mathrm{C} 1$ & $\begin{array}{r}\text { Simple response to a key alarm within a range of ala } \\
\text { indication of situation (simple diagnosis required). Res } \\
\text { simple actions or initiating other actions }\end{array}$ & 0.0004 & $1.667 \cdot 10^{-5}$ & 59988.00 & 14995 \\
\hline $\mathrm{C} 2$ & $\begin{array}{l}\text { Identification of situation requiring interpretation of complex pattern } \\
\text { indications. (Note that the response component should be evaluated as a s }\end{array}$ & 0.2000 & $9.298 \cdot 10^{-3}$ & 107.55 & 117 \\
\hline
\end{tabular}

LHR method is structured in the following steps.

Equation (5) considers a working time greater than eight hours because in several emergencies, some operators could work even 24 hours consecutive.

Step 4: External Factors Definition.

The environmental influences are modeled with the use of PSFs [13]. The PSFs increase the HEP values. The PSFs analyzed are as follows:

(i) Available time

(ii) Stress/stressor

(iii) Complexity

(iv) Experience and training

(v) Procedures

(vi) Ergonomics and human-machine interface (HMI)

(vii) Fitness for duty

(viii) Work processes

Other PSFs could be analyzed in particular accident scenarios; however, PSFs dependencies are not considered in the NARA model. Starting from the analysis of 82 incidents at the USA nuclear plants, Boring (2010) proposed a table of PSFs dependencies (Table 3 ).

Step 5: PSFs Correlation ( $\mathrm{PSF}_{\text {cor }}$ ).

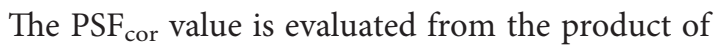
all PSFs and their value of independence (Table 3 ). The PSF cor $_{\text {represents the external environmental }}$ conditions as shown in equation (6):

$$
\operatorname{PSF}_{\text {cor }}=\prod_{i=1}^{n}\left[\operatorname{PSF}_{i}\left(1-\sum \text { dependence_indexs }\right) \cdot \operatorname{State}\left(\mathrm{PSF}_{i}\right)\right] .
$$

According to Gertman et al. [13], the PSFi value is the individual value of PSFs, where " $n$ " is the total number of $\mathrm{PSF}_{\mathrm{S}}$ considered in the approach. The state of each PSF has been assessed by an Expert Judgment $\left(0<\right.$ State $\left.\left(\mathrm{PSF}_{\mathrm{i}}\right)<1\right)$.

Step 6: PSFs Corrected by Time ( $\left.\mathrm{PSF}_{\text {time }}\right)$.

The results obtained from equation (6) are corrected by time factors.

$$
T=\frac{t}{8}
$$

where $1 \leq t \leq 24$.

Applying the following equation (8), we obtained the PSFs corrected by time:

$$
\mathrm{PSF}_{\text {time }}=\mathrm{PSF}_{\mathrm{cor}} \cdot T \text {. }
$$

Equation (8) is able to increase PSFs after the $8^{\text {th }}$ hour of work. In this condition, the influence of external factors is more important for operators. Step 7: LHR Model (HEP $\left.{ }_{\text {LHR }}\right)$. 
TABLE 3: PSFs dependence

\begin{tabular}{|c|c|c|c|c|c|c|c|c|}
\hline & $\begin{array}{c}\text { Available } \\
\text { time }\end{array}$ & $\begin{array}{c}\text { Stress/ } \\
\text { stressors }\end{array}$ & Complexity & $\begin{array}{l}\text { Experience } \\
\text { training }\end{array}$ & Procedures & $\begin{array}{c}\text { Ergonomics } \\
\text { HMI }\end{array}$ & $\begin{array}{c}\text { Fitness for } \\
\text { duty }\end{array}$ & $\begin{array}{c}\text { Work } \\
\text { process }\end{array}$ \\
\hline Available time & 1 & & & & & & & \\
\hline Stress/stressors & $0.50^{*}$ & 1 & & & & & & \\
\hline Complexity & $0.38^{*}$ & $0.35^{*}$ & 1 & & & & & \\
\hline $\begin{array}{l}\text { Experience } \\
\text { Training }\end{array}$ & $0.31^{*}$ & $0.21^{*}$ & $0.32^{*}$ & 1 & & & & \\
\hline Procedures & 0.05 & -0.01 & $0.12^{*}$ & $0.08^{*}$ & 1 & & & \\
\hline $\begin{array}{l}\text { Ergonomics } \\
\text { HMI }\end{array}$ & $0.10^{*}$ & 0.04 & $0.08^{*}$ & $0.08^{*}$ & $0.29^{*}$ & 1 & & \\
\hline Fitness for duty & $0.20^{*}$ & $0.29^{*}$ & $0.22^{*}$ & $0.17^{*}$ & $0.12^{*}$ & $0.27^{*}$ & 1 & \\
\hline Work process & 0 & $0.13^{*}$ & $0.16^{*}$ & $0.20^{*}$ & $0.35^{*}$ & $0.12^{*}$ & $0.15^{*}$ & 1 \\
\hline
\end{tabular}

*Significant correlation with $p$ value $<0.05$.

Starting from NARA formulations, the real HEP is calculated. The combination of human factors and environmental factors returns the $\mathrm{HEP}_{\mathrm{LHR}}$ value:

$$
\mathrm{HEP}_{\text {SHRA }}=\mathrm{HEP}_{\text {basic }} \cdot\left[\mathrm{PSF}_{\text {time }}+1\right]
$$

$\mathrm{HEP}_{\text {SHRA }}$ is the unreliability value of the operator during an accident scenario, depending on the influencing factors.

\section{Case Study: LHR Application in a Pharmaceutical Plant}

A pharmaceutical plant (Figure 1) is considered to validate our model. To develop the LHR approach, we used NARA and SPAR-H methods (designed for nuclear plants) since the consequences of disaster in a pharmaceutical plant could cause tragic consequences for the operators and the external environment.

In particular, the HEP in a control room is analyzed (Figure 2).

\section{Step 1: Preliminary Analysis}

The emergency activities of the decision-makers in the control room of a pharmaceutical plant during a fire are summarized in the following steps:

(i) Emergency alarm activation

(ii) Emergency signal activation

(iii) Protection system activation

(iv) Evacuation of personnel

(v) System block

(vi) External alarm activation

(vii) Insolation of damaged area

(viii) Internal Emergency Team activation

(ix) Request for external aid The three simulation scenarios are as follows:

(a) Weak accident: the decision-maker has the situation under control (PSFs values are good).

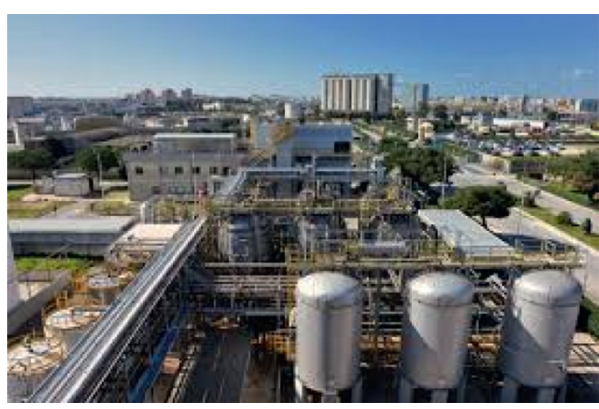

Figure 1: Pharmaceutical plant.

(b) Medium accident: the decision-maker can make bad decisions (PSFs values are average).

(c) Worst accident: likely the operator made a wrong choice (PSFs values are bad).

Step 2: Identification of Human Activities.

The major causes of accidents are to be found in the human unreliability of the decision-maker assigned to the control room. The case study focuses on the analysis of human reliability in the control room during emergency conditions. The operator in the control room manages simple and complex actions. The choice of four GTTs [30] was carried out through interviews with an Expert Judgment. Applying equations (2)-(4), the four GTTs are related to the four activities managed by the decision-maker described in Step 1 (Table 4).

Step 3: Basic Human Error Probability $\left(\mathrm{HEP}_{\text {basic }}\right)$ Using equation (5), $\mathrm{HEP}_{\text {basic }}$ is calculated. Table 5 describes $\mathrm{HEP}_{\text {basic }}$ values during 24 working hours (Table 5).

Step 4: External Factors Definition.

According to an Expert Judgment, PSFs values have been selected. The analysis emphasized five fundamental factors [61]:

(i) Available time: the time needed to receive, check, and process the information and make the decision; 


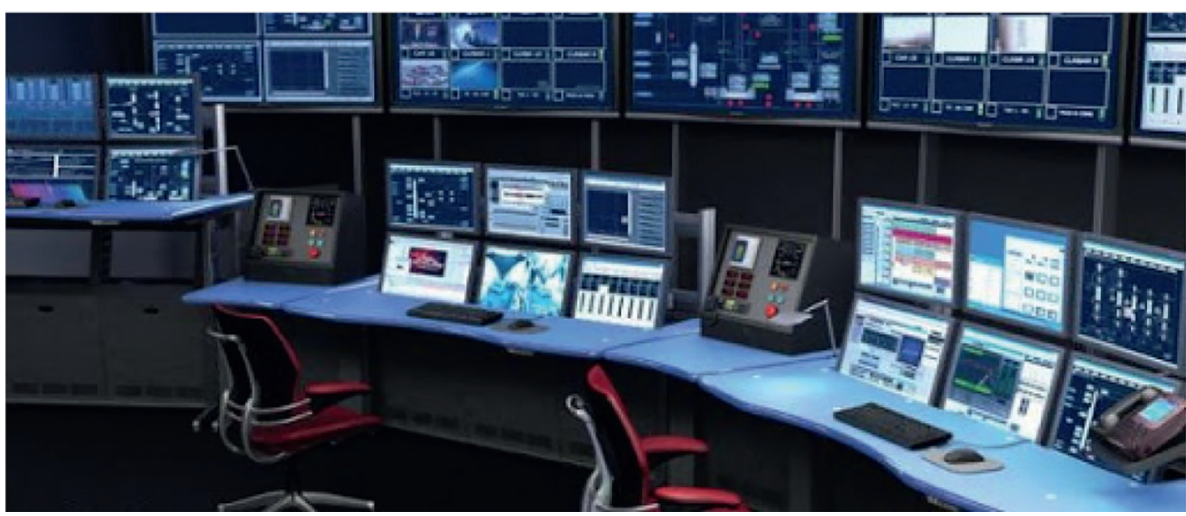

FIgURE 2: Control room in a pharmaceutical plant.

TABLE 4: GTTs of the control room operator.

\begin{tabular}{|c|c|c|c|c|c|}
\hline $\mathrm{N}^{\circ}$ & GGT & $\begin{array}{c}\mathrm{K} 24 \\
(t=24 \mathrm{~h})\end{array}$ & $\lambda[1 / \mathrm{h}]$ & $\mu(\mathrm{h})$ & $\sigma(\mathrm{h})$ \\
\hline A5 & $\begin{array}{l}\text { Judgment needed for appropriate procedure to be followed, based on interpretation of } \\
\text { alarms/indications, situation covered by training at appropriate intervals. }\end{array}$ & 0.0100 & $4.188 \cdot 10^{-4}$ & 2387.98 & 1004 \\
\hline A6 & $\begin{array}{l}\text { Completely familiar, well-designed highly practiced, routine task performed to highest } \\
\text { possible standards by highly motivated, highly trained, and experienced person, totally } \\
\text { aware of implications of failure, with time to correct potential error. Note that this is a } \\
\text { special case. }\end{array}$ & 0.0001 & $4.167 \cdot 10^{-6}$ & 239988.00 & 59995 \\
\hline B5 & Carry out a & 0.0300 & $1.269 \cdot 10^{-3}$ & 787.94 & 413 \\
\hline $\mathrm{C} 2$ & $\begin{array}{l}\text { Identification of situation requiring interpretation of } \mathrm{cc} \\
\text { indications. (Note that the response component should be }\end{array}$ & 0.2000 & $9.298 \cdot 10^{-3}$ & 107.55 & 117 \\
\hline
\end{tabular}

TABle 5: $\mathrm{HEP}_{\text {basic. }}$

\begin{tabular}{lllll}
\hline & \multicolumn{4}{c}{ HEP $_{\text {basic }}$} \\
& GTT-A5 & GTT-A6 & GTT-B5 & GTT-C2 \\
\hline$t=2 \mathrm{~h}$ & $4.17 \cdot 10^{-2}$ & $6.15 \cdot 10^{-2}$ & $1.01 \cdot 10^{-1}$ & $1.17 \cdot 10^{-2}$ \\
$t=4 \mathrm{~h}$ & $7.10 \cdot 10^{-2}$ & $7.18 \cdot 10^{-2}$ & $1.25 \cdot 10^{-1}$ & $3.10 \cdot 10^{-2}$ \\
$t=6 \mathrm{~h}$ & $9.23 \cdot 10^{-2}$ & $1.33 \cdot 10^{-1}$ & $1.93 \cdot 10^{-1}$ & $6.23 \cdot 10^{-2}$ \\
$t=8 \mathrm{~h}$ & $1.26 \cdot 10^{-1}$ & $2.28 \cdot 10^{-1}$ & $2.98 \cdot 10^{-1}$ & $8.26 \cdot 10^{-2}$ \\
$t=12 \mathrm{~h}$ & $1.51 \cdot 10^{-1}$ & $2.81 \cdot 10^{-1}$ & $3.11 \cdot 10^{-1}$ & $1.11 \cdot 10^{-1}$ \\
$t=10 \mathrm{~h}$ & $2.26 \cdot 10^{-1}$ & $3.36 \cdot 10^{-1}$ & $3.86 \cdot 10^{-1}$ & $1.25 \cdot 10^{-1}$ \\
$t=14 \mathrm{~h}$ & $2.89 \cdot 10^{-1}$ & $3.81 \cdot 10^{-1}$ & $3.99 \cdot 10^{-1}$ & $1.99 \cdot 10^{-1}$ \\
$t=16 \mathrm{~h}$ & $3.41 \cdot 10^{-1}$ & $4.10 \cdot 10^{-1}$ & $4.45 \cdot 10^{-1}$ & $2.31 \cdot 10^{-1}$ \\
$t=18 \mathrm{~h}$ & $3.91 \cdot 10^{-1}$ & $4.61 \cdot 10^{-1}$ & $5.23 \cdot 10^{-1}$ & $2.56 \cdot 10^{-1}$ \\
$t=20 \mathrm{~h}$ & $4.25 \cdot 10^{-1}$ & $4.99 \cdot 10^{-1}$ & $5.99 \cdot 10^{-1}$ & $3.05 \cdot 10^{-1}$ \\
$t=22 \mathrm{~h}$ & $5.15 \cdot 10^{-1}$ & $5.91 \cdot 10^{-1}$ & $6.02 \cdot 10^{-1}$ & $3.99 \cdot 10^{-1}$ \\
$t=24 \mathrm{~h}$ & $5.98 \cdot 10^{-1}$ & $6.17 \cdot 10^{-1}$ & $6.19 \cdot 10^{-1}$ & $4.21 \cdot 10^{-1}$ \\
\hline
\end{tabular}

(ii) Stress: the degree to which you feel overwhelmed or unable to cope as a result of pressures that are unmanageable;

(iii) Complexity: the complexity of task performing;

(iv) Experience: the competence and seniority of the decision-maker;

(v) Procedures: risk management of nuclear plants.

Table 6 describes the PSFs values and Table 7 reports the PSFs correlation (Boring, 2010).

Table 7 is reproduced from Falcone et al. [62], under the Creative Commons Attribution License/ public domain.
TABle 6: PSFs values.

\begin{tabular}{lccc}
\hline PSF & Low hazard & Medium hazard & High hazard \\
\hline Available time & 0.1 & 1 & 10 \\
Stress & 0.2 & 2 & 20 \\
Complexity & 0.1 & 1 & 10 \\
Experience & 0.1 & 1 & 10 \\
Procedures & 0.3 & 3 & 30 \\
\hline
\end{tabular}

Step 5: PSFs Correlation ( $\mathrm{PSF}_{\text {cor }}$ )

According to equation (6) and considering state $(P S F)=0.2$ for each performance shaping factor, $\mathrm{PSF}_{\text {cor }}$ index was calculated:

$\mathrm{PSF}_{\mathrm{cor}}=[10 \cdot 1 \cdot 0.2] \cdot\left[\begin{array}{ll}20 & (1-0.50) \cdot 0.2\end{array}\right] \cdot\left[\begin{array}{ll}10 & (1-0.38-\end{array}\right.$ $0.35) \cdot 0.2] \cdot[10 \quad(1-0.32-0.21-0.31) \cdot 0.2] \cdot[30 \quad(1-0.08-$ $0.12+0.01-0.05) \cdot 0.2]=0.192(8)$.

Step 6: PSFs Corrected by Time ( $\left.\mathrm{PSF}_{\text {time }}\right)$.

According to equations (7) and (8), we obtained the PSFs corrected by time (Table 8 ).

$\mathrm{PSF}_{\text {time }}$ value is equal to $\mathrm{PSF}_{\text {cor }}$ value at the $8^{\text {th }}$ working hour but assumes a triple value for the $24^{\text {th }}$ working hour.

Applying PSF $_{\text {time }}$ we will obtain the following outputs:

(i) An increase of $\mathrm{HEP}_{\text {basic }}$ at the $2^{\text {nd }}$ working hour equal to $4.8 \%$

(ii) An increase of $\mathrm{HEP}_{\text {basic }}$ at the $8^{\text {th }}$ working hour equal to $19.2 \%$ 
TABLE 7: PSFs dependence.

\begin{tabular}{|c|c|c|c|c|c|}
\hline & Available time & Stress/stressors & Complexity & $\begin{array}{c}\text { Experience } \\
\text { training }\end{array}$ & Procedures \\
\hline Available time & 1 & & & & \\
\hline $\begin{array}{l}\text { Stress } \\
\text { Stressors }\end{array}$ & $0.50^{*}$ & 1 & & & \\
\hline Complexity & $0.38^{*}$ & $0.35^{*}$ & 1 & & \\
\hline $\begin{array}{l}\text { Experience } \\
\text { Training }\end{array}$ & $0.31^{*}$ & $0.21^{*}$ & $0.32^{*}$ & 1 & \\
\hline Procedures & 0.05 & -0.01 & $0.12^{*}$ & $0.08^{*}$ & 1 \\
\hline
\end{tabular}

TABLE 8: Time factors.

\begin{tabular}{lcc}
\hline & $\mathrm{T}$ & $\mathrm{PSF}_{\text {time }}$ \\
\hline$t=2 \mathrm{~h}$ & 0.25 & 0.048 \\
$t=4 \mathrm{~h}$ & 0.50 & 0.096 \\
$t=6 \mathrm{~h}$ & 0.75 & 0.144 \\
$t=8 \mathrm{~h}$ & 1.00 & 0.192 \\
$t=10 \mathrm{~h}$ & 1.25 & 0.24 \\
$t=12 \mathrm{~h}$ & 1.50 & 0.288 \\
$t=14 \mathrm{~h}$ & 1.75 & 0.336 \\
$t=16 \mathrm{~h}$ & 2.00 & 0.384 \\
$t=18 \mathrm{~h}$ & 2.25 & 0.432 \\
$t=20 \mathrm{~h}$ & 2.50 & 0.48 \\
$t=22 \mathrm{~h}$ & 2.75 & 0.528 \\
$t=24 \mathrm{~h}$ & 3.00 & 0.576 \\
\hline
\end{tabular}

(iii) An increase of $\mathrm{HEP}_{\text {basic }}$ at the $12^{\text {th }}$ working hour equal to $28.8 \%$

(iv) An increase of $\mathrm{HEP}_{\text {basic }}$ at the 24th working hour equal to $57.6 \%$

Step 7: LHR Human Error Probability $\left(\mathrm{HEP}_{\mathrm{LHR}}\right)$

Applying equation (9), $\mathrm{HEP}_{\mathrm{LHR}}$ has been evaluated by combining internal operating conditions $\left(\mathrm{HEP}_{\text {basic }}\right)$ with external environment conditions corrected by $T$ factor ( $\left.\mathrm{PSF}_{\text {time }}\right)$. Table 9 shows the $\mathrm{HEP}_{\mathrm{LHR}}$ values for the GTTs during the high hazardous scenario and Figure 3 describes the $\mathrm{HEP}_{\mathrm{LHR}}$ trends.

\section{Discussion}

The operator's choices in emergency conditions depend on many factors. In some cases, the decision-maker can take wrong actions. The HEP of the operator generates high risks for the company. In this condition, HEP is influenced by human factors, environmental factors (PSFs), and working time.

The proposed model analyzes the HEP and it simulates the real analysis process of a decision-maker who works in a control room of a pharmaceutical plant.

$\mathrm{HEP}_{\mathrm{LHR}}$ increases with operating time due to human factors because the decision-maker will be tired during the working time. $\mathrm{HEP}_{\mathrm{LHR}}$ for GTT-A5 in the 2 nd hour is $4.37 \%$, while at the 24 th hour, it is $94.24 \%$. However, the human unreliability depends also on the GTTs. The results highlight that GTT-B5 is the most relevant task, $\operatorname{HEP}_{\mathrm{LHR}}(t=24 \mathrm{~h})=$ $97.55 \%$, while GTT-C2 is the less relevant task, HEP ${ }_{\text {LHR }}$ $(t=24 \mathrm{~h})=66.35 \%$.
TABLE 9: HEP LHR $_{\text {. }}$

\begin{tabular}{lcccc}
\hline & \multicolumn{4}{c}{ HEP $_{\text {LHR }}$} \\
& GTT-A5 (\%) & GTT-A6 & GTT-B5 (\%) & GTT-C2 (\%) \\
\hline$t=2 \mathrm{~h}$ & 4.37 & $6.45 \%$ & 10.58 & 1.23 \\
$t=4 \mathrm{~h}$ & 7.78 & $7.87 \%$ & 13.70 & 3.40 \\
$t=6 \mathrm{~h}$ & 10.56 & $15.22 \%$ & 22.08 & 7.13 \\
$t=8 \mathrm{~h}$ & 15.02 & $27.18 \%$ & 35.52 & 9.85 \\
$t=10 \mathrm{~h}$ & 18.72 & $34.84 \%$ & 38.56 & 13.76 \\
$t=12 \mathrm{~h}$ & 29.11 & $43.28 \%$ & 49.72 & 16.10 \\
$t=14 \mathrm{~h}$ & 38.61 & $50.90 \%$ & 53.31 & 26.59 \\
$t=16 \mathrm{~h}$ & 47.19 & $56.74 \%$ & 61.59 & 31.97 \\
$t=18 \mathrm{~h}$ & 55.99 & $66.02 \%$ & 74.89 & 36.66 \\
$t=20 \mathrm{~h}$ & 62.90 & $73.85 \%$ & 88.65 & 45.14 \\
$t=22 \mathrm{~h}$ & 78.69 & $90.30 \%$ & 91.99 & 60.97 \\
$t=24 \mathrm{~h}$ & 94.24 & $97.24 \%$ & 97.55 & 66.35 \\
\hline
\end{tabular}

The "identification of a situation requiring interpretation of complex patterns of alarms/indications" is a less complex task for an expert operator than other analyzed tasks during an emergency that could last for 24 working hours.

The approach defines support to minimize HEP. The outputs show that HEP depends on time, human factors, and environmental factors. The $\mathrm{HEP}_{\mathrm{LHR}}$ output highlighted the following improvements:

(i) Improvement in the work processes, e.g., work breaks, ergonomics, statistical process control, and logistic quality

(ii) Improvement of reliability system

(iii) Improvement of safety system

(iv) Improvement of the maintenance system

(v) Improvement by training on the job

In order to verify the proposed method, we have compared the values obtained by the application of NARA and SHAR-H techniques with LHR data.

In NARA, HEP is calculated by the following equation (equation (10)):

$$
\operatorname{HEP}_{\text {Nara }}=\operatorname{HEP}_{i} \times \prod_{j=1}^{n}\left\{\left[\text { Weight }\left(\mathrm{PSF}_{j}\right)-1\right] \times \operatorname{State}\left(\mathrm{PSF}_{j}\right)+1\right\},
$$

where $\mathrm{N}$ is the number of applicable PIFs and $0 \leq$ State $\left(\mathrm{PSF}_{j}\right) \leq 1$

In SHAR-H, HEP is calculated by the following equation (equation (11)): 


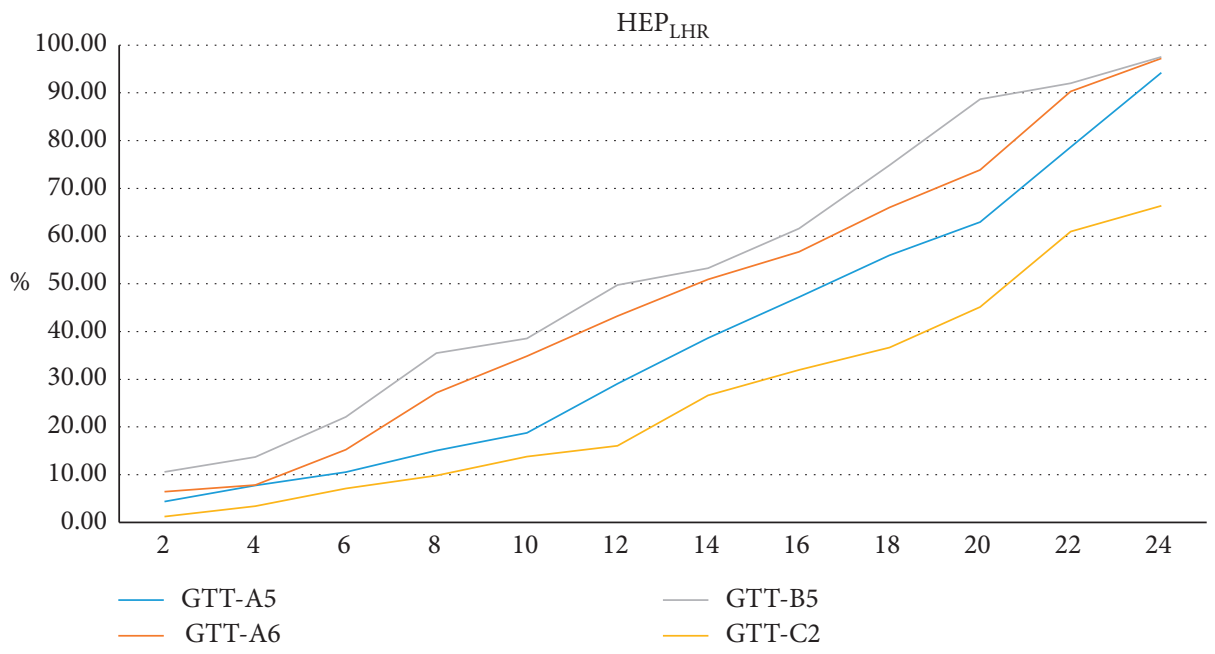

Figure 3: HEP LHR $_{\text {. }}$

$$
\mathrm{HEP}_{\mathrm{SPAR}-H}=\frac{\mathrm{NHEP} \times \mathrm{PSF}_{\text {composite }}}{\mathrm{NHEP} \times\left(\mathrm{PSF}_{\text {composite }}-1\right)+1},
$$

where NHEP is the respective nominal HEP for Diagnosis

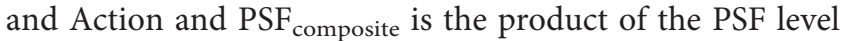
multipliers. This formula will ensure that the individual Diagnosis and Action HEP values do not exceed a probability limit of 1.0 .

Applying equations (10) and (11), we obtained for GTTA6 (the most generic tasks) the following results (Table 10):

$\mathrm{HEP}_{\mathrm{LHR}}, \mathrm{HEP}_{\mathrm{NARA}}$, and $\mathrm{HEP}_{\mathrm{SPAR}-\mathrm{H}}$ were compared with the International HRA Empirical data.

The International HRA Empirical Study is a multinational and multiteam study organized by the Organization for Economic Cooperation and Development (OECD) Halden Reactor Project, the Swiss Federal Nuclear Safety Inspectorate, the U.S. Electric Power Research Institute, and the U.S. Nuclear Regulatory Commission (NRC). The study's objective was to develop an empirically based understanding of the performance, strengths, and weaknesses of different HRA methods used to model human response to accident sequences in probabilistic risk assessments (PRAs) [63].

The empirical data used in the study were collected during experiments performed at Halden Reactor Project's HAMMLAB (HAlden huMan-Machine LABoratory) research simulator, where crews from a nuclear power plant responded to simulated accident scenarios. The scenarios were chosen to be similar to pharmaceutical disaster scenarios. The data collected were interpreted by Halden experimentalists to fit HRA data needs. This package contained information regarding the scenarios and human actions to be assessed and descriptions of the operational culture at the crews' home plant and the combined experience of the crews. The procedures used in the simulator runs were also provided. After the teams had conducted the analyses and submitted them to the organizations, an independent group of experts compared the results of each HRA method/team to the empirical data. Thirteen different HRA methods (14 analyses in total, including two teams performing the analysis using the same
TABLE 10: HEP NARA $_{\text {and HEP }}$ SPAR-H for GTT-A6.

\begin{tabular}{lcc}
\hline & \multicolumn{2}{c}{ GTT-A6 } \\
& HEP $_{\text {NARA }}$ & HEP $_{\text {SPAR-H }}$ \\
\hline$t=2 \mathrm{~h}$ & $8.56 \%$ & 5.26 \\
$t=4 \mathrm{~h}$ & $9.89 \%$ & 6.25 \\
$t=6 \mathrm{~h}$ & $17.82 \%$ & 14.01 \\
$t=8 \mathrm{~h}$ & $31.33 \%$ & 23.50 \\
$t=10 \mathrm{~h}$ & $36.58 \%$ & 31.05 \\
$t=12 \mathrm{~h}$ & $48.50 \%$ & 38.60 \\
$t=14 \mathrm{~h}$ & $52.63 \%$ & 41.01 \\
$t=16 \mathrm{~h}$ & $59.60 \%$ & 49.48 \\
$t=18 \mathrm{~h}$ & $69.98 \%$ & 53.69 \\
$t=20 \mathrm{~h}$ & $78.36 \%$ & 66.65 \\
$t=22 \mathrm{~h}$ & $89.96 \%$ & 75.78 \\
$t=24 \mathrm{~h}$ & $98.01 \%$ & 88.92 \\
\hline
\end{tabular}

HRA method) were compared to empirical human performance data. Among the HRA methods participating in the study were THERP, ATHEANA, SPAR-H, and HEART. As noted earlier, more information about the scenarios and the International HRA Empirical Study as a whole can be found in the NUREG/IA-0216 and the Halden Work Reports [64, 65].

Subsequently, we have compared the $\mathrm{HEP}_{\text {LHR }}$, HEPNARA, and $\mathrm{HEP}_{\mathrm{SPAR}-\mathrm{H}}$ results for GTT-A6 with the HEP empirical data, obtained from International HRA Empirical Study and modified for pharmaceutical disaster scenarios. Then, we calculated the Mean Absolute Deviation percentile (MAD) of negative technological errors (ć) between HEP values calculated $\left(\mathrm{HEP}_{\mathrm{LHR}}, \mathrm{HEP}_{\mathrm{NARA}}\right.$, and $\left.\mathrm{HEP}_{\text {SPAR-H }}\right)$ and HEP values of databanks (Table 11).

In particular, the negative technological error is defined according to equation (12):

$$
\varepsilon_{\text {technological }_{i}}=\left[\mathrm{HEP}_{\text {LHR/NARA/SPAR-H }}-\mathrm{HEP}_{\text {Data }}\right] \text {, }
$$

and MAD is defined according to equation (13):

$$
\text { MAD }=\frac{\sum_{i=1}^{n}\left|\varepsilon_{\text {technolocigal }_{i}}\right|}{n} .
$$




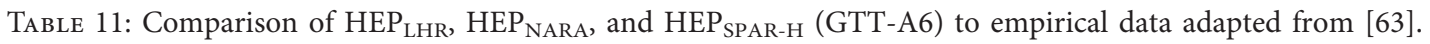

\begin{tabular}{|c|c|c|c|c|c|c|c|c|c|}
\hline & $\begin{array}{l}\mathrm{HEP}_{\mathrm{LHR}} \\
(\%)\end{array}$ & $H E P_{\text {Data }}$ & $\dot{\varepsilon}(\%)$ & $\mathrm{HEP}_{\text {NARA }}$ & $H E P_{\text {Data }}$ & $\dot{\varepsilon}(\%)$ & $\begin{array}{l}\mathrm{HEP}_{\text {SPAR- }} \\
\mathrm{H}(\%)\end{array}$ & $H E P_{\text {Data }}$ & $\dot{\varepsilon}(\%)$ \\
\hline$t=2 \mathrm{~h}$ & 6.45 & $6.45 \%$ & $7.12 \%$ & $-0.67 \%$ & $8.56 \%$ & $7.12 \%$ & 1.44 & $5.26 \%$ & $7.12 \%$ \\
\hline$t=4 \mathrm{~h}$ & 7.87 & $7.87 \%$ & $8.42 \%$ & $-0.55 \%$ & $9.89 \%$ & $8.42 \%$ & 1.47 & $6.25 \%$ & $8.42 \%$ \\
\hline$t=6 \mathrm{~h}$ & 15.22 & $15.22 \%$ & $15.89 \%$ & $-0.67 \%$ & $17.82 \%$ & $15.89 \%$ & 1.93 & $14.01 \%$ & $15.89 \%$ \\
\hline$t=8 \mathrm{~h}$ & 27.18 & $27.18 \%$ & $28.89 \%$ & $-1.71 \%$ & $31.33 \%$ & $28.89 \%$ & 2.44 & $23.50 \%$ & $28.89 \%$ \\
\hline$t=10 \mathrm{~h}$ & 34.84 & $34.84 \%$ & $34.99 \%$ & v0.15\% & $36.58 \%$ & $34.99 \%$ & 1.59 & $31.05 \%$ & $34.99 \%$ \\
\hline$t=12 \mathrm{~h}$ & 43.28 & $43.28 \%$ & $41.45 \%$ & $1.83 \%$ & $48.50 \%$ & $41.45 \%$ & 7.05 & $38.60 \%$ & $41.45 \%$ \\
\hline$t=14 \mathrm{~h}$ & 50.90 & $50.90 \%$ & $49.56 \%$ & $1.34 \%$ & $52.63 \%$ & $49.56 \%$ & 3.07 & $41.01 \%$ & $49.56 \%$ \\
\hline$t=16 \mathrm{~h}$ & 56.74 & $56.74 \%$ & $51.12 \%$ & $5.62 \%$ & $59.60 \%$ & $51.12 \%$ & 8.48 & $49.48 \%$ & $51.12 \%$ \\
\hline$t=18 \mathrm{~h}$ & 66.02 & $66.02 \%$ & $63.25 \%$ & $2.77 \%$ & $69.98 \%$ & $63.25 \%$ & 6.73 & $53.69 \%$ & $63.25 \%$ \\
\hline$t=20 \mathrm{~h}$ & 73.85 & $73.85 \%$ & $70.58 \%$ & $3.27 \%$ & $78.36 \%$ & $70.58 \%$ & 7.78 & $66.65 \%$ & $70.58 \%$ \\
\hline$t=22 \mathrm{~h}$ & 90.30 & $90.30 \%$ & $85.69 \%$ & $4.61 \%$ & $89.96 \%$ & $85.69 \%$ & 4.27 & $75.78 \%$ & $85.69 \%$ \\
\hline \multirow[t]{3}{*}{$t=24 \mathrm{~h}$} & 97.24 & $97.24 \%$ & $92.63 \%$ & $4.61 \%$ & $98.01 \%$ & $92.63 \%$ & 5.38 & $88.92 \%$ & $92.63 \%$ \\
\hline & & $\sum\left(-\dot{\varepsilon}_{\text {technological }}\right)_{\mathrm{LHR}}$ & $-3.75 \%$ & & $\sum\left(-\dot{\varepsilon}_{\text {technological }}\right)_{\text {NARA }}$ & $0.00 \%$ & & $\sum\left(-\dot{\varepsilon}_{\text {technological }}\right)_{\text {SPAR- }}$ & $-55.39 \%$ \\
\hline & & $M A D_{L H R}$ & $2.32 \%$ & & $M A D_{N A R A}$ & $4.30 \%$ & & $M A D_{S P A R-H}$ & $4.62 \%$ \\
\hline
\end{tabular}

If $\mathrm{HEP}_{\text {LHR/NARA/SPAR-H }}<\mathrm{HEP}_{\text {DATA }}$, we obtain a negative technological error and $\varepsilon_{\text {technological }}$ values highlight the criticalities of the HEP method, in particular, the sum $\sum$ $\left(-\dot{\varepsilon}_{\text {technological }}\right)$.

The result shows that the LHR method obtains a more reasonable HEP rating than the conventional methods.

The sum $\sum\left(-\dot{\varepsilon}_{\text {technological }}\right)$ for LHR is the minimum $\left(\sum(-\dot{\varepsilon})=-3.75\right)$ in relation to $\sum\left(-\dot{\varepsilon}_{\text {technological }}\right)$ for SPAR-H, but not in relation to $\sum\left(-\dot{\varepsilon}_{\text {technological }}\right)$ for NARA. The reason is that Logit-Normal function is selected during the stress phase of an operator in an accident scenario (after the $12^{\text {th }}$ hour). The $\mathrm{HEP}_{\mathrm{LHR}}$ results matched better $\mathrm{HEP}_{\mathrm{DATA}}$ after the $12^{\text {th }}$ working hour. In fact, the MAD for LHR is the minimum $\left(\mathrm{MAD}_{\mathrm{LHR}}=2.32 \%\right)$ in relation to MAD for NARA and MAD for SPAR-H. In conclusion, it is possible to affirm that the new methodology gives output data more in conformity with databanks during the stress phase of an operator in an accident scenario (after the $12^{\text {th }}$ hour) $[66,67]$.

\section{Conclusion}

The aim of the present article is to propose a new method to evaluate HEP, called LHR. This study was developed for identifying and evaluating human error in control rooms in a pharmaceutical plant. The proposed approach considers all factors that influence the decisions and actions of the operator: internal and external factors and time indexes.

The main characteristics and innovative aspects of the proposed approach are as follows:

(i) LHR method considers human (internal) factors and environmental (external) factors, which influence the operator's ability.

(ii) LHR method considers logit-normal distribution to link HEP and operating time during the emergency conditions.

(iii) LHR method considers PSFs dependencies.

(iv) LHR method considers a Time Factor $(T)$ to correct PSFs dependencies. (v) LHR method considers working time more than 8 hours during emergency conditions.

(vi) LHR method gives output data more in conformity with data banks than the conventional methods during the stress phase in an accident scenario $\left(\mathrm{MAD}_{\mathrm{LHR}}=2.32 \%\right.$ in GTT-A6).

Even if the LHA method is a simple and convenient method to evaluate the reliability of humans, we find some disadvantages in its application. They include ambiguity and overlap in definitions of PSFs; expertise requirements; even biases in the expert's judgment. Future research aims to develop a statistic function on evaluate States (PSFs) without Expert Judgment, using a multidecision model (e.g., AHP/ ANP or Fuzzy Logic).

\section{Data Availability}

The data used to support the findings of this study are included within the article.

\section{Conflicts of Interest}

The authors declare no conflicts of interest.

\section{Authors' Contributions}

The manuscript was approved by all authors for publication. G. Di Bona conceived and designed the study. L. Silvestri and F. De Carlo collected and analyzed the data. G. Di Bona and A. Forcina wrote the manuscript. D. Falcone reviewed and edited the manuscript. All authors have read and agreed to the published version of the manuscript.

\section{References}

[1] D. R. Harris and G. C. Hillman, Foraging and Farming: The Evolution of Plant Exploitation, Routledge, New York, NY, USA, 2014.

[2] F. De Felice, A. Petrillo, and F. Zomparelli, "A hybrid model for human error probability analysis," IFAC-PapersOnLine, vol. 49, no. 12, pp. 1673-1678, 2016. 
[3] T. B. Sheridan and W. R. Ferrell, Man-machine Systems; Information Control and Decision Models of Human Performance, The MIT press, Cambridge, MA, USA, 1974.

[4] X. Zhou, Y. Shi, X. Deng, and Y. Deng, "D-DEMATEL: a new method to identify critical success factors in emergency management," Safety Science, vol. 91, pp. 93-104, 2017.

[5] F. De Felice and A. Petrillo, "Methodological approach for performing human reliability and error analysis in railway transportation system," International Journal of Engineering and Technology, vol. 3, no. 5, pp. 341-353, 2011.

[6] G. Di Bona, V. Duraccio, A. Silvestri, and A. Forcina, "February). Validation and application of a safety allocation technique (integrated hazard method) to an aerospace prototype," in Proceedings of the IASTED International Conference on Modelling Identification and Control MIC, Innsbruck, Austria, February 2014.

[7] M. Reznek, R. Smith-Coggins, S. Howard et al., "Emergency Medicine Crisis Resource Management (EMCRM): pilot study of a simulation-based crisis management course for emergency medicine," Academic Emergency Medicine, vol. 10, no. 4, pp. 386-389, 2003.

[8] R. Janius, K. Abdan, and Z. A. Zulkaflli, "Development of a disaster action plan for hospitals in Malaysia pertaining to critical engineering infrastructure risk analysis," International Journal of Disaster Risk Reduction, vol. 21, pp. 168-175, 2017.

[9] Z. Scott and R. Few, "Strengthening capacities for disaster risk management I: insights from existing research and practice," International Journal of Disaster Risk Reduction, vol. 20, pp. 145-153, 2016.

[10] H. Lu, H. Zhen, W. Mi, and Y. Huang, “A physically based approach with human-machine cooperation concept to generate assembly sequences," Computers \& Industrial Engineering, vol. 89, pp. 213-225, 2015.

[11] A. Shanmugam and T. Paul Robert, "Ranking of aircraft maintenance organization based on human factor performance," Computers \& Industrial Engineering, vol. 88, pp. 410-416, 2015.

[12] B. Kirwan, H. Gibson, R. Kennedy, J. Edmunds, G. Cooksley, and I. Umbers, "Nuclear action ReliabilityAssessment (NARA): a data-based HRA tool," in The 7th Probabilistic Safety Assessment and ManagementSpringer, Berlin Germany, 2004.

[13] D. I. Gertman, H. S. Blackman, J. L. Marble, J. C. Byers, and C. L. Smith, "The SPAR-H human reliability analysis method," U.S. Nuclear Regulatory Commission NUREG/CR6883 INL/EXT-05-00509, Washington, NJ, USA, 2005.

[14] R. L. Boring, "How many performance shaping factors are necessary for human reliability analysis?" in Proceedings Of the 10th International Probabilistic Safety Assessment \& Management Conference (PSAM10), pp. 32-42, Seattle, WA. USA, June 2010.

[15] I. S. Kim, "Human reliability analysis in the man-machine interface design review," Annals of Nuclear Energy, vol. 28, no. 11, pp. 1069-1081, 2001.

[16] A. D. Swain and H. E. Guttmann, "Handbook of humanreliability analysis with emphasis on nuclear power plant applications," Final Report, Sandia National Labs, Albuquerque, NM, USA, 1983.

[17] P. Lundqvist and B. Gustafsson, "Accidents and accident prevention in agriculture a review of selected studies," International Journal of Industrial Ergonomics, vol. 10, no. 4, pp. 311-319, 1992.

[18] E. Hollnagel, "Reliability analysis and operator modelling," Reliability Engineering \& System Safety, vol. 52, no. 3, pp. 327-337, 1996.
[19] F. De Carlo, M. Tucci, and O. Borgia, "Conception of a prototype to validate a maintenance expert system," International Journal of Engineering and Technology, vol. 5, no. 5, pp. 4273-4282, 2013.

[20] F. De Carlo, M. A. Arleo, and M. Tucci, "OEE evaluation of a paced assembly line through different calculation and simulation methods: a case study in the pharmaceutical environment," International Journal of Engineering Business Management, vol. 6, no. Godište 2014, pp. 6-27, 2014.

[21] P. S. Magnusson, M. Christensson, J. Eskilson et al., "Simics: a full system simulation platform," Computer, vol. 35, no. 2, pp. 50-58, 2002.

[22] W. Jung, J. Park, J. Kim, and J. Ha, “Analysis of an operators' performance time and its application to a human reliability analysis in nuclear power plants," IEEE Transactions on Nuclear Science, vol. 54, no. 5, pp. 1801-1811, 2007.

[23] A. Houshyar and G. Imel, "A simulation model of the fuel handling system in a nuclear reactor," Computers \& Industrial Engineering, vol. 30, no. 1, pp. 117-135, 1996.

[24] G. W. Hannaman and A. J. Spurgin, "Systematic human action reliability procedure (SHARP)," Interim Report, NUS Corporation, San Diego USA, 1984.

[25] G. W. Hannaman, A. J. Spurgin, and Y. Lukic, "A model for assessing human cognitive reliability in PRA studies," in Proceedings of the Conference Record for 1985 IEEE Third Conference on Human Factors and Nuclear Safety, Monterey, CA, USA, June 1985.

[26] M. Čepin, "Importance of human contribution within the human reliability analysis (IJS-HRA)," Journal of Loss Prevention in the Process Industries, vol. 21, no. 3, pp. 268-276, 2008.

[27] W. H. Elmaraghy, O. A. Nada, and H. A. ElMaraghy, "Quality prediction for reconfigurable manufacturing systems via human error modelling," International Journal of Computer Integrated Manufacturing, vol. 21, no. 5, pp. 584-598, 2008.

[28] G. C. Bello and V. Colombari, "The human factors in risk analyses of process plants: the control room operator model 'TESEO'," Reliability Engineering, vol. 1, no. 1, pp. 3-14, 1980.

[29] J. C. Williams, "Validation of human reliability assessment techniques," Reliability Engineering, vol. 11, no. 3, pp. 149-162, 1985.

[30] J. C. Williams, "HEART-a proposed method for assessing and reducing human error," in Proceedings of the Ninth Advances in Reliability Technology Symposium, Culcheth, UK, April 1986.

[31] Y. Yang, X. Chen, J. Zhang, and R. Kang, "Human reliability test and identification of HCR model basic parameters for multi-factor "Meta-Operation"” in Safety and Reliability: Methodology and Applications, pp. 1025-1032, CRC Press, Boca Raton, FL, USA, 2014.

[32] P. J. Xu, Q. Y. Peng, C. Wen, J. W. Guo, and S. G. Zhan, "Human reliability analysis on high-speed train dispatcher based on THERP and Markov theories," Journal of Transportation Systems Engineering and Information Technology, vol. 14, no. 6, pp. 133-140, 2014.

[33] K. S. Park and J. i. Lee, "A new method for estimating human error probabilities: ahp-slim," Reliability Engineering \& System Safety, vol. 93, no. 4, pp. 578-587, 2008.

[34] S. G. Kariuki and K. Löwe, "Integrating human factors into process hazard analysis," Reliability Engineering \& System Safety, vol. 92, no. 12, pp. 1764-1773, 2007.

[35] N. Van and X. F. He, "Experience from adapting structured HRA methods to the oil and gas industry," The Annual European Safety and Reliability Conference, vol. 2, pp. 1019-1025, 2012. 
[36] B. Kirwan, "the validation of three human reliability quantification techniques-THERP HEART and JHEDI: Part 1technique descriptions and validation issues," Applied Ergonomics, vol. 27, no. 6, pp. 359-373, 1996.

[37] F. Colangelo, "The human factor in risk assessment methods in the workplace," Italian Journal of Occupational and Environmental Hygiene, vol. 3, no. 1, pp. 49-53, 2012.

[38] M. Konstandinidou, Z. Nivolianitou, C. Kiranoudis, and N. Markatos, "A fuzzy modeling application of CREAM methodology for human reliability analysis," Reliability Engineering \& System Safety, vol. 91, no. 6, pp. 706-716, 2006.

[39] J. M. O. Pinto, P. F. F. E. Melo, and P. L. C. Saldanha, “A DFM/ Fuzzy/ATHEANA human failure analysis of a digital control system for a pressurizer," Nuclear Technology, vol. 188, no. 1, pp. 20-33, 2014.

[40] M. Rasmussen, M. I. Standal, and K. Laumann, “Task complexity as a performance shaping factor: a review and recommendations in Standardized plant analysis risk-human reliability analysis (SPAR-H) adaption," Safety Science, vol. 76, pp. 228-238, 2015.

[41] V. Di Pasquale, R. Iannone, S. Miranda, and S. Riemma, “An overview of human reliability analysis techniques in manufacturing operations," in Operations Management, M. M. Schiraldi, Ed., Intech, Palm Beach, FL, USA, 2013.

[42] R. Boring, Human Reliability Analysis Methods for Space safety. RMC Session G: Human Error and Risk Assessment, 2005.

[43] I. Rauschert, P. Agrawal, R. Sharma, S. Fuhrmann, I. Brewer, and A. MacEachren, "Designing a human-centered multimodal GIS interface to support emergency management," in Proceedings of the 10th ACM international symposium on Advances in geographic information systems, McLean, VA, USA, November 2002.

[44] M. De Ambroggi and P. Trucco, "Modelling and assessment of dependent performance shaping factors through Analytic Network Process," Reliability Engineering \& System Safety, vol. 96, no. 7, pp. 849-860, 2011.

[45] P. Trucco and M. C. Leva, "A probabilistic cognitive simulator for HRA studies (PROCOS)," Reliability Engineering \& System Safety, vol. 92, no. 8, pp. 1117-1130, 2007.

[46] W. A. Schafer, C. H. Ganoe, and J. M. Carroll, "Supporting community emergency management planning through a geocollaboration software architecture," Computer Supported Cooperative Work, vol. 16, no. 4-5, pp. 501-537, 2007.

[47] P. Currion, C. D. Silva, and B. Van De Walle, "Open source software for disaster management," Communications of the ACM, vol. 50, no. 3, pp. 61-65, 2007.

[48] L. Levi, D. Bregman, H. Geva, and M. Revach, "Hospital disaster management simulation system," Prehospital and Disaster Medicine, vol. 13, no. 1, pp. 22-27, 1998.

[49] M. L. Cowan and M. Cloutier, "Medical simulation for disaster casualty management training," The Journal of Trauma and Acute Care Surgery, vol. 28, no. 1, pp. S178-S182, 1988.

[50] P. M. J. Christie and R. R. Levary, "The use of simulation in planning the transportation of patients to hospitals following a disaster," Journal of Medical Systems, vol. 22, no. 5, pp. 289-300, 1998.

[51] E. Calixto, G. B. A. Lima, and P. R. A. Firmino, "Comparing SLIM SPAR-H and Bayesian network methodologies," Open Journal of Safety Science and Technology, vol. 03, no. 02, pp. 31-41, 2013.

[52] L.-X. Hou, R. Liu, H.-C. Liu, and S. Jiang, "Two decades on human reliability analysis: a bibliometric analysis and literature review," Annals of Nuclear Energy, vol. 151, p. 107969, February 2021.

[53] H.-C. Liu, Z. Li, J.-Q. Zhang, and X.-Y. You, "A large group decision making approach for dependence assessment in human reliability analysis," Reliability Engineering \& System Safety, vol. 176, pp. 135-144, 2018.

[54] V. Duraccio, D. Di Falcone, G. Bona, A. Silvestri, and A. Forcina, "Chemical risk evaluation: application of the Movarish methodology in an industry of the textile sector," in Proceedings of the 27th European Modeling and Simulation Symposium EMSS, pp. 451-456, Bergeggi, Italy, September 2015.

[55] V. Di Pasquale, S. Miranda, R. Iannone, and S. Riemma, "A simulator for human error probability analysis (SHERPA)," Reliability Engineering \& System Safety, vol. 139, pp. 17-32, 2015.

[56] D. I. Gertman and H. S. Blackman, Human Reliability and Safety Analysis Data Handbook, John Wiley \& Sons, New York, NY, USA, 1994.

[57] E. Chiodo, F. Gagliardi, and M. Pagano, "Human reliability analyses by random hazard rate approach," COMPEL-The International Journal for Computation and Mathematics in Electrical and Electronic Engineering, vol. 23, no. 1, pp. 65-78, 2004.

[58] B. Kirwan, H. Gibson, R. Kennedy, J. Edmunds, G. Cooksley, and I. Umbers, "Nuclear action ReliabilityAssessment (NARA): a data-based HRA tool," Safety \& Reliability Journal, vol. 25, no. 2, 2005.

[59] D. McLoughlin, "A framework for integrated emergency management," Public Administration Review, vol. 45, pp. 165-172, 1985.

[60] D. Mendonca, G. E. G. Beroggi, and W. A. Wallace, "Decision support for improvisation during emergency response operations," International Journal of Emergency Management, vol. 1, no. 1, pp. 30-38, 2001.

[61] I. E. Allen and C. A. Seaman, "Likert scales and data analyses," Quality Progress, vol. 40, no. 7, pp. 64-65, 2007.

[62] D. Falcone, F. De Felice, A. Petrillo, and A. Silvestri, An Experimental Study on Developing a Cognitive Model for Human Reliability Analysis, Theory and Application on Cognitive Factors and Risk Management Published, 2017.

[63] E. Lois, V. N. Dang, J. Forester et al., International HRA Empirical Study -Phase 1 Report, U.S Nuclear Regulatory Commission, Washington, NJ, USA, 2009.

[64] E. Lois, V. N. Dang, J. Forester et al., International HRA Empirical Study-Pilot Phase Report: Description of Overall Approach and First Pilot Results from Comparing HRA Methods to Simulator Data" HWR 844, OECD Halden Reactor Project, Halden, Norway, 2009.

[65] E. Lois, V. N. Dang, G. Parry et al., "The International HRA Empirical Study - Results from Comparing HRA Methods Predictions to HAMMLAB Simulator Data on SGTR Scenarios" HWR 915, OECD Halden Reactor Project, Halden, Norway, 2010.

[66] G. Di Bona, D. Falcone, A. Forcina, and L. Silvestri, "Systematic human reliability analysis (shra): a new approach to evaluate human error probability (HEP) in a nuclear," Plant International Journal of Mathematical Engineering and Management Sciences, vol. 6, no. 1, pp. 345-362, 2021.

[67] A. Petrillo, D. Falcone, F. De Felice, and F. Zomparelli, "Development of a risk analysis model to evaluate human error in industrial plants and in critical infrastructures," International Journal of Disaster Risk Reduction, vol. 23, pp. 15-24, 2017. 